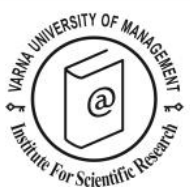

\title{
Hudson, S. (2020). COVID-19 \& Travel Impacts, Responses and Outcomes. ISBN: 9781911635703, Oxford, UK: Goodfellow Publishers Ltd.
}

\begin{abstract}
Reviewed by
Alberto Amore ${ }^{1 *}$

${ }^{1}$ Solent University Southampton, United Kingdom. Email: alberto.amore@solent.ac.uk

${ }^{*}$ Corresponding author

Citation: Amore, A. (2022). Book review of Hudson, S. (2020). COVID-19 \& Travel Impacts, Responses and Outcomes. ISBN: 9781911635703, Oxford, UK: Goodfellow Publishers Ltd. European Journal of Tourism Research 30 3022.
\end{abstract}


The year 2020 will indelibly be associated with COVID19 and its impact on our lives and daily routines. This global pandemic affected each one of us, both individually and professionally. The ongoing media coverage and sequence of events that unfolded showed different levels of preparedness and lack thereof from health authorities, government officials and businesses in general. The travel and tourism industry was not the exception, with examples of swift adaptability and resilience alongside gross vulnerabilities and negligence from the outbreak to the ongoing management of the crisis.

Undeniably, the amount of information and examples from the sector is remarkable and at times hard to follow and report. I, therefore, found COVID-19 E Travel Impacts, Responses and Outcomes as a much-needed contribution to report and account for the hundreds of stories and initiatives within a constructed macro-narrative. The author - Simon Hudson - collated a nice and valuable snapshot of the year 2020 for travel and tourism. The reporting style is straightforward and practical for anyone seeking to have a sound appraisal of crisis management response among different stakeholders and organizations in the industry.

This valuable contribution is structured in 6 thematic chapters. Chapter 1 provides a much-needed reflection on the role of global travel and tourism in the spread of the pandemic. Global travel before COVID19 hit a record-high of 1.5 billion international tourist arrivals in 2019. The chapter provides a valuable account of key events that ultimately culminated with the closure of borders and tight restrictions to international travel. In terms of content and industry insights, most of the chapter illustrates the contingency plans put in place in a selected range of destinations, with examples from local and national DMOs. Arguably, the chapter would have benefited from a greater emphasis on the impact of COVID19 and subsequent restrictions in the hospitality sector. A focus on hospitality and leisure SMEs would have provided a better appraisal of the impact and extent of the COVIDig pandemic in the sector.

Chapter 2 focuses on the initiatives and responses of the travel and tourism industry as a result of the lockdown measures across countries. The content of the chapter is extremely rich, and the narrative is very easy to follow. The author did a great job in providing an international perspective that underpinned the global nature of the travel and tourism sector. Of particular interest are the responses and examples of leadership addressed in the two dedicated case studies. The variety and range of examples provided across the chapter are remarkable, but I believe there was scope for a stronger analytical underpinning. Arguably, the author could have used one of the established crisis and disaster management frameworks in travel and tourism to discuss the plenty of empirical evidence presented in the chapter.

Crisis communication is addressed in detail in Chapter 3. This aspect of crisis response is crucial in the early stages of the crisis and the long-term recovery of destinations. The author presents several initiatives and dedicated case studies from both national and urban DMOs. A good extent of the examples provided in the chapter focuses on marketing initiatives combining traditional place branding with health and safety communication. The chapter provides a wide range of examples from European destinations, including post-crisis and cause-related marketing initiatives. That being said, I think the chapter has a limited appraisal of the latest advancements and works on crisis communication management in the travel and tourism industry. Greater coordination between empirical evidence and the body of knowledge would have further reinforced the analytical underpinning of the chapter.

Chapter 4 seeks to address the impact of COVID on the demand. The author provides plenty of examples and perspectives for readers to reflect upon. Building from the case of two travellers, the 
chapter sheds light on demand-relevant issues that surfaced as a result of the COVID19 pandemic. Travel insurance issues, blatant negligence among travellers, adaptability to quarantine and social distancing measures are among the key aspects addressed in the chapter. A section on virtual events and tours provides much-needed empirical evidence on the role of technology and digitalization in travel and tourism during the pandemic. Overall, the chapter emphasizes initiatives and responses relevant to destination marketing and social media marketing. However, the chapter fails to address psychological and behavioural responses to the demand. There are recent insights from recent works on the impact of COVIDig on travel demand that could have been included in the chapter.

The impacts of COVID19 are the focus of Chapter 5. The chapter provides a legit a valuable appraisal of the economic impacts of the pandemic, with a range of estimates from both international and national authorities with an interest in travel and tourism. The section on social impacts delves into the consequences of COVID19 in scarcely dense areas and the potential exposure of rural destinations to exceeding and unwelcome tourists during the summer of 2020. The section on environmental impacts acknowledges the likely fallacies on government response to the need for a quick economic recovery despite concerning levels of $\mathrm{CO}_{2}$ and the issue of climate change before the pandemic. However, the section does not adequately address key environmental and ecological issues that are likely to be exacerbated in destinations when movement restrictions will be lifted.

The last chapter (Chapter 6) seeks to provide an appraisal as to what will be the future of travel in a post-pandemic world. However, most of the observations and comments provided in the chapter are already underway or were due to happen despite the pandemic. The narrative of the chapter underpins mainstream "business as usual" rhetoric that has echoed among professionals and most academics. Arguably, the chapter provides some room for reflection on what the future of travel and tourism will be in the so-called "new normal". However, the chapter falls short in providing a much-needed structural and bold vision of the future of travel and tourism.

Having read the book, I believe that COVID-19 E Travel Impacts, Responses and Outcomes is a valuable and much-needed contribution illustrating the impact, response, adaptability, and challenges that global travel and tourism faced during the annus horribilis of 2020. The author did quite a remarkable job in collating different perspectives and aspects of COVID19 and travel in a dense and empirically driven narrative that best suits professionals in tourism and hospitality and undergraduate students. Arguably, researchers might find this work of relevance if they seek to conduct further research on one of the many insights provided across the chapters.

Received: 13/07/2021

Accepted: 14/o7/2021

Coordinating editor: Stanislav Ivanov 